\title{
Health in Colombia: the chronic disease burden
}

D r. Aida Lebbos Saad hatched the idea while working as a pediatrician in an upscale private clinic within Colombia's capital city of Bogotá. She'd noticed that children from wealthy families were changing - by ballooning.

As Colombia's economy surged, it seemed the children of the privileged were becoming heavier and unhealthier, as a result of richer diets, sedentary lifestyles and decreased physical activity.

She sensed a business opportunity: a health centre for affluent Colombian kids. The notion was reinforced when the results of a 2010 national nutrition survey indicated that over a five-year period, there had been a $10 \%$ increase in the number of overweight and obese Colombians, including children. Some $25 \%$ of children aged 5-17 had excess body mass. In some parts of the country, that tally was as high as $31 \%$, roughly equivalent to childhood obesity rates in the United States, which have been labelled epidemic.

"The data convinced me that affluent kids in Colombia face the same health problems as kids in rich countries, where childhood obesity opens the path to chronic diseases such as diabetes and hypertension later in life," Lebbos says. "That's why I quit my clinical job to start a fitness centre for kids."

She called it "Fun4Fit" - an English name that automatically confers international prestige in a Spanishspeaking country. The clinic, which Lebbos calls novel for Colombia, offers a comprehensive program of physical exercise and dietary education for wealthy kids. Located in the penthouse of an upscale building in one of Bogotá's toniest neighbourhoods, it aims to help the obese offspring of the affluent "get in shape while learning about basic nutrition," says Lebbos. "I think there is a real need for this. And I think people will pay for it."

In a country oft-defined by poverty and war, where it's been estimated that

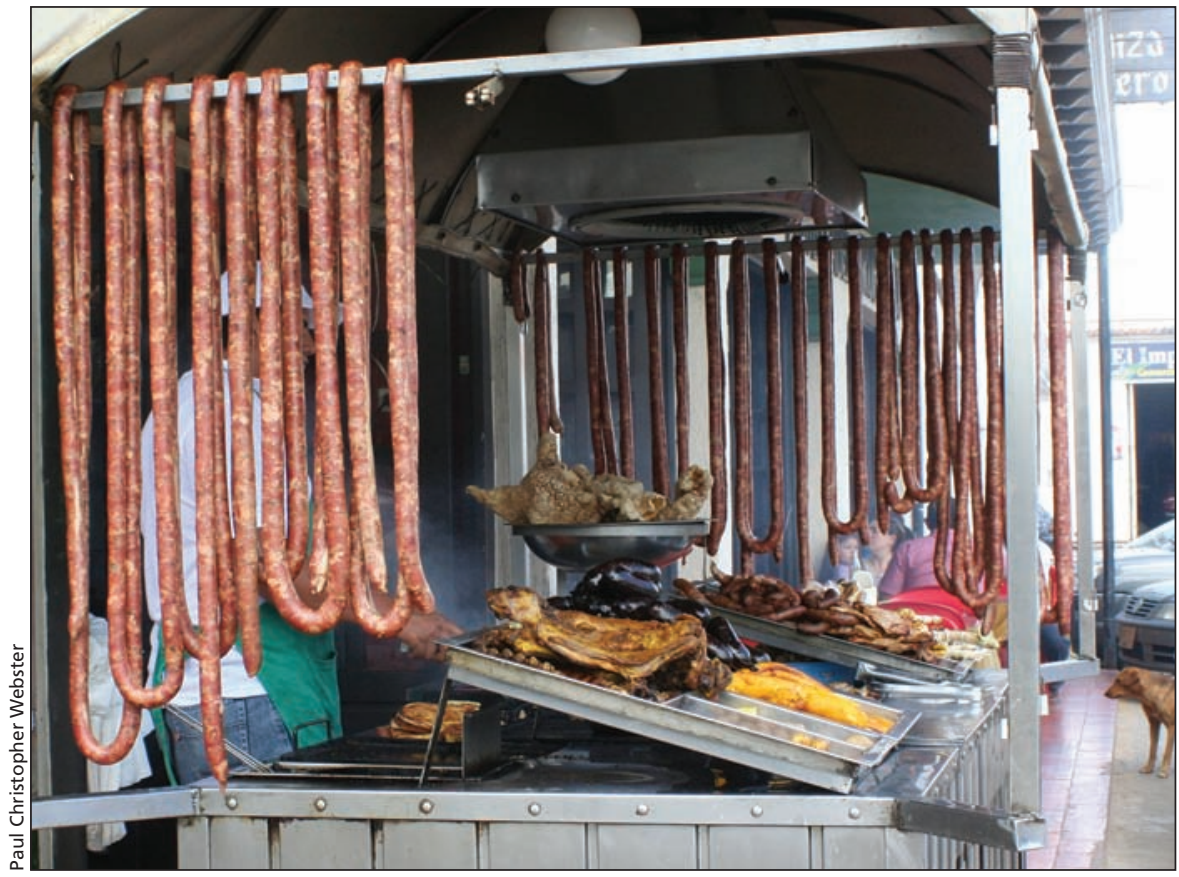

A meat stand in Bogotá, Colombia, a country in which 8 of the 10 leading causes of mortality are chronic or noncommunicable diseases.

at least $10 \%$ of the population are undernourished, obesity among the affluent might seem to be a marginal problem.

But as many developing countries are discovering, the wave of chronic and noncommunicable diseases that stem from conditions like obesity, is posing major challenges for their health care systems. Such diseases are estimated to take a toll of 36 million deaths annually $-80 \%$ of them in developing nations. The spiralling tally led to the 2011 United Nations summit on noncommunicable diseases, at which the 193-member UN General Assembly adopted a consensus declaration calling on the World Health Organization (WHO) to develop a set of global targets before the end of 2012 to monitor trends and progress in the battle to reduce death and disability from noncommunicable diseases (www.un.org/en /ga/ncdmeeting2011/pdf/NCD_draft _political_declaration.pdf). The declaration commits governments to strengthen their national health sys- tems and policies to make more of an effort to prevent and treat noncommunicable diseases and to integrate policies aimed at reducing the impact of the diseases more directly into national health and economic development plans (www.cmaj.ca/lookup/doi/10 .1503/cmaj.109-4010).

Yet while WHO and other global mandarins mull the options, pediatricians like Lebbos and health care systems like that of Colombia are left to seek on-the-ground solutions.

Precise, up-to-date numbers on chronic disease levels in Colombia are difficult to obtain, although the Center of Development Projects at Pontificia Universidad Javeriana in Bogotá estimates that the total burden of chronic disease increased $40 \%$ between 1995 and 2005. Eight of the 10 leading causes of mortality in Colombia are chronic or noncommunicable diseases, according to the Mission of Colombia to the United Nations (www.un.org/esa/population /cpd/cpd2010/Country_Statements 
/AgendaItem4/COLOMBIA.pdf). In 2002, noncommunicable diseases accounted for $68.1 \%$ of 243747 deaths in Colombia, according to the Pan American Health Organization (www .paho.org/english/ad/dpc/nc/carmen-col ombia.pdf). Cardiovascular disease was the leading contributor, with age standardized mortality ratio of 239 per 100 000, followed by malignant neoplasms (116 per 100 000), chronic respiratory diseases (54 per 100000$)$ and diabetes (32 per 100000 ).

"It's a problem that Colombia has to tackle immediately," says Dr. Luis Fernando Gomez, professor of pathology at the Faculty of Medicine at Pontificia Universidad Javeriana in Bogotá. "The biggest change is what is happening to children: We can't wait until we have problems on the scale of the US [United States] and Canada. Obesity was at first concentrated among the wealthiest but we are now on the path where it is also affecting the poorest."

A "reduction in cholesterol levels, blood pressure and obesity is a priority to control the ongoing epidemic of cardiovascular diseases," which has been estimated to be the cause of $40 \%$ of deaths in Colombia, concurs Dr. Leon Bautista, assistant professor of popula- tion health services at the University of Wisconsin in Madison.

Gomez and a consortium of nutritionists pressed the government of Colombia into passing an "anti-obesity law" in 2009 that promotes mass physical exercise and regulates school nutrition and food and beverage marketing. But in the face of resistance from the processed food industry, implementation has been an obstacle, Gomez says. "Although the government passed a very progressive law on this issue, it continues to view health promotion mostly as a matter of personal lifestyle choice. That lets them wash their hands of taking further action."

As evidence of government inaction, Gomez cites the gradual whittling of road space allocated to Bogotá's famous "Ciclovia" program, which closes major streets in this city of nine million on Sundays to promote walking and biking. Between 1990 and 2002, the city invested $\$ 180$ million to create 291 kilometres of dedicated bicycle paths and by 2003 , the number of trips made by bicycles, as opposed to other forms of transportation, had increased to $4.4 \%$ from $0.058 \%$.

Some 38 cities in 11 countries have followed Bogota's lead and a study found that the benefits of Ciclovia programs outweigh the costs ( $J$ Urban Health 2011 Dec 15 [Epub ahead of print]).

But with automobile ownership exploding in Bogotá, the program was reduced. It's a retreat that flies in the face of public health, Gomez argues. "As the cities of Colombia and elsewhere in the developing world increasingly mimic the car-oriented settlement patterns of first-world cities, the same kinds of chronic diseases and obesity problems associated with physical inactivity in the United States and other car-based societies will arise." - Paul Christopher Webster, Bogotá, Colombia

CMAJ 2012. DOI:10.1503/cmaj.109-4126

Editor's note: Third of a three-part series on health in Colombia.

Part 1: A system in crisis (www.cmaj.ca/lookup/doi/10.1503 /cmaj.109-4124).

Part 2: Treating the displaced (www.cmaj.ca/lookup/doi/10.1503 /cmaj.109-4125). 